\title{
Radiofrequency thermocoagulation of Gasserian ganglion and its rootlets for trigeminal neuralgia
}

\author{
R P SENGUPTA, R J STUNDEN
}

British Medical fournal, 1977, 1, 142-143

\begin{abstract}
Summary
Thirty-nine patients with trigeminal neuralgia, not controlled by medical treatment, were treated by radiofrequency thermocoagulation of the Gasserian ganglion and its posterior rootlets. Thirty-six received satisfactory pain relief. In 30 patients touch sensation in the treated territory was preserved. The corneal reflex was affected in only six patients, two of whom subsequently developed keratitis. There were no other complications apart from a minor unpleasant sensation in eight patients.

By selectively destroying pain fibres this technique offers the scope of preserving touch sensation in the treated area. Moreover, the zone of analgesia can be restricted to the affected region by sensory mapping through electrode stimulation before thermocoagulation. Its simplicity, low morbidity, associated short hospital stay, and the increased ability to preserve touch sensation, especially of the cornea, seem to make it preferable to other forms of surgical management for trigeminal neuralgia.
\end{abstract}

\section{Introduction}

Tic douloureux is a disease known from antiquity. Until the introduction of carbamazepine ${ }^{1}$ there was no satisfactory medical treatment for this benign yet cruel condition, which often occurs in frail elderly people. In drug-resistant cases the injection of chemicals into Meckel's cave or open operation still remain the procedures of choice. Recently, however, the technique of controlled thermocoagulation of the Gasserian ganglion and its posterior rootlets by a radiofrequency lesion has largely replaced all other surgical procedures in North America and some parts of Europe. This technique, however, has not been widely adopted in Britain. We report here our experience with this technique in 39 patients with trigeminal neuralgia.

\section{Patients and methods}

From January 1975 to August 197639 patients with trigeminal neuralgia were admitted for treatment using this technique. As expected the patients were predominantly female and elderly (table I). Each patient had typical trigeminal neuralgia. Some had predisposing factors leading to the symptoms: three patients (aged 34, 48, and 49) had multiple sclerosis, one (aged 32) had a septum in the foramen

TABLE I-Age distribution

\begin{tabular}{r|c|c|c|c|c|c}
\hline Age (years): & $31-40$ & -50 & -60 & -70 & -80 & -90 \\
No of patients: & 4 & 1 & 16 & 10 & 7 & 1 \\
\hline
\end{tabular}

Regional Neurological Centre, Newcastle General Hospital, Newcastle upon Tyne NE4 6BE

R P SENGUPTA, MB, FRCS, senior registrar in neurosurgery

R J STUNDEN, MB, DA, rotating registrar in surgery ovale, and one (aged 32) had had tuberculous meningitis. This confirms the accepted view that trigeminal neuralgia in the young is likely to be secondary to an organic lesion.

Nearly half of the patients had suffered for more than five years $\frac{\mathrm{\sigma}}{\widehat{\Phi}}$ (table II). Most patients had received carbamazepine for at least twoe years, many with other drugs as well, but two were submitted to thermocoagulation without prior medical treatment. Carbemazepinelost its effect in 22 patients and had no effect in six. It is interesting. that nine patients, some of whom had also received various forms of $\overrightarrow{-}$ surgical management, could not tolerate the drug. Patients who obtained benefit from carbamazepine were not treated by thermo-을 coagulation.

Isolated first-division involvement was seen in only one case,whereas combined involvement of the first and second divisions was common (table III). There was one case of bilateral neuralgia; that on the right side had been successfully relieved by root section 13 years: previously, but the patient had refused an operation on the left.

TABLE II-Duration of symptoms
\begin{tabular}{r|c|c|c|c|c|c|c|c} 
Duration (years): & $<1$ & -2 & -3 & -4 & -5 & -10 & $>10$ \\
No of patients: & 6 & 8 & 4 & 2 & 2 & 8 & 9 \\
\hline
\end{tabular}

TABLE III-Division of trigeminal nerve affected by neuralgia

\begin{tabular}{c|l|l|l|l|l|l|l|}
$\begin{array}{c}\text { Division: } \\
\text { No of patients: }\end{array}$ & 1 & 2 & 3 & 1 and 2 & 2 and 3 & 1,2 , and 3 \\
\hline
\end{tabular}

PROCEDURE AND TECHNICAL AIDS

Our technique is that of Sweet and Wepsic'2 with some modifications The availability of skilled anaesthetists in Britain has made the procedure relatively simple using intermittent intravenous anaesthesia. Although there are several varieties of specially designed apparatus available for this purpose, we have been able to perform the technique without difficulty using parts assembled in our workshop. The essential 3 technical aids are: (a) an operating table with an adjustable head resto incorporating a cassette holder; this enables the position of the head to윽 be changed for $x$-ray purposes; (b) portable $x$-ray apparatus; (c) $10-\mathrm{cm}$ 20 -gauge hollow needle with an insulated shaft (electrode); $(d)$ nerve윽 stimulator; (e) device for recording the temperature of the electroden tip (thermister); $(f)$ radiofrequency source; $(g)$ intermittent intravenous anaesthesia.

We have found the following anaesthetic regimen satisfactory. The patient was predmedicated with intramuscular atropine $0 \cdot 2-0.3 \mathrm{O}$ $\mathrm{mg}$ one hour before operation. An intravenous infusion was set up at the beginning of the procedure. Droperidol $5 \mathrm{mg}$ and fentanyl $0.05 \mathrm{mg}$ were given intravenously to produce basal sedation; further increments of these were given later as required. Methohexitone $10-40 \mathrm{mg}$ was administered intravenously before penetration of the foramen ovale and each episode of thermocoagulation; this small dose was adequate + for producing unconsciousness and immobility. It is important to avoid airways obstruction or apnoea by restricting the dose of anaesthetic to a minimum. The blood pressure, pulse, and electro- $\cap$ cardiogram were monitored; the respiratory rate was not allowed to $\mathbb{Q}$ fall below 15/minute, and a careful watch was maintained to ensure ano adequate airway. For a typical procedure the following total doses were used: droperidol 5-10 mg, fentanyl 0.05-0.1 mg, methohexitone 150-O $300 \mathrm{mg}$. At the end of the operation naloxone $0.4 \mathrm{mg}$ intravenously was sometimes given to ensure that there was no postoperative respiratoryo depression.

The patient was placed supine on an operating table. Local anaesthetic (procaine $1 \%$ ) was infiltrated at the proposed site of entry of the electrode, $2 \frac{1}{2}-3 \mathrm{~cm}$ lateral to the corner of the mouth. The 
electrode was then advanced towards the foramen ovale using Hertel's approach, a dose of methohexitone being given before penetration of the foramen, as this is normally painful. The position of the electrode tip was checked on lateral and submento-occipital views of plain skull radiographs; when difficulty was encountered in locating the foramen ovale these views were of considerable help in adjusting the electrode's path.

An indifferent electrode was placed in the scalp and, with the patient conscious, a low voltage current was passed through the exploring electrode to determine the exact location of its tip within the trigeminal rootlets. Its position was changed if necessary. The patient felt a variable sensation in the distribution of the root or roots thus stimulated A response was usually obtained with a stimulation of $0 \cdot 2-0.4$ volts; failure to achieve this indicated that the electrode tip needed adjustment. When its tip was finally positioned a thermister was inserted through the electrode and a radiofrequency source attached.

Under a short methohexitone anaesthetic the electrode tip was heated to $60 \mathrm{C}$ for two minutes. The patient was then allowed to waken, and sensation to pin-prick was tested in the appropriate dermatome. Further lesions were made at higher temperatures until analgesia was obtained in the required territory, taking care to preserve the corneal reflex during each period of thermocoagulation. For effective pain relief it was essential to obtain analgesia of the trigger area. All medication was stopped, and the patient could go home the next day.

\section{Results}

As we started performing this technique in January 1975, we have followed up patients for only 2 to 20 months, and this should be taken into account when considering the success rate in this series. One elderly woman with first-division pain was treated by this technique in the National Hospital for Nervous Diseases, London, in collaboration with Professor V Logue. Although she could not be followed up in the normal way, satisfactory analgesia of the required division was not achieved and pain has recurred. This failure may have resulted from the rather cautious attempt at thermocoagulation necessitated by the patient being blind in the contralateral eye. Apart from this patient, all the others were regularly followed up in the outpatient clinic.

In three other patients satisfactory analgesia of the affected division was not obtained at operation; two of these patients also had an affected first division. At follow-up analgesia was found to have regressed in a further four, but 36 patients were free of pain (table IV). It is interesting to note that two patients in whom satisfactory analgesia was not obtained at operation have remained free of pain for 15 and 12 months. Likewise three other patients have remained free of pain although analgesia of the affected division has regressed completely. Of the three patients with a recurrence of pain one was not referred for a second thermocoagulation and the other two have had only partial return of symptoms and do not yet want a further procedure. Nine patients lost the sensation of touch in the treated division, but the remaining 30 could feel touch to a varying degree.

Of the 12 patients with first-division pain, either alone or with pain in other divisions also, nine obtained analgesia in the first division

TABLE IV-Effect of thermocoagulation and pain relief

\begin{tabular}{l|c|c|c}
\hline & $\begin{array}{c}\text { No of } \\
\text { patients }\end{array}$ & $\begin{array}{c}\text { No with } \\
\text { pain relief }\end{array}$ & $\begin{array}{c}\text { No with } \\
\text { recurrence }\end{array}$ \\
\hline $\begin{array}{c}\text { Analgesia to required division } \\
\text { sustained at follow-up }\end{array}$ & 31 & 31 & 0 \\
$\begin{array}{c}\text { Analgesia regressed from required } \\
\text { division }\end{array}$ & 4 & 3 & 1 \\
$\begin{array}{c}\text { Analgesia to required division not } \\
\text { obtained at operation }\end{array}$ & 4 & 2 & 2 \\
\hline
\end{tabular}

TABLE v-First division analgesia and sequelae

\begin{tabular}{l|c|c|c|c}
\hline & $\begin{array}{c}\text { Total No } \\
\text { of patients }\end{array}$ & $\begin{array}{c}\text { No with } \\
\text { analgesia }\end{array}$ & $\begin{array}{c}\text { No with } \\
\text { loss of } \\
\text { corneal reflex }\end{array}$ & $\begin{array}{c}\text { No with } \\
\text { keratitis }\end{array}$ \\
\hline $\begin{array}{l}\text { For first-division pain } \\
\text { For other divisions }\end{array}$ & $\mathbf{1 2}$ & 9 & $4^{*}$ & 1 \\
\hline
\end{tabular}

*One patient, who had multiple sclerosis, had an absent corneal reflex before *One patient, who
thermocoagulation. (table V) but only one suffered keratitis through loss of corneal reflex. Eight had unintentional first-division analgesia when thermocoagulation was performed for neuralgia affecting other divisions of the trigeminal nerve, but only three of these patients lost their corneal reflex, one of whom suffered keratitis.

There were no cases of anaesthesia dolorosa. Eight patients admitted some unpleasant sensation in their face, but most were grateful for the pain relief. Although there was no motor palsy, some of the unpleasant sensations could be related to weakness of the tensor palati muscle affecting the Eustachian tube. ${ }^{3}$ There was no cranial nerve injury outside the trigeminal field.

\section{Discussion}

Although the follow-up was relatively short, our preliminary results with this technique are encouraging. Thirty-six patients out of 39 obtained satisfactory relief of pain when all medical treatment had failed. Conventional injection techniques ${ }^{45}$ or intracranial procedures are effective alternatives. But uncontrollable spread of alcohol or phenol is the main drawback of the injection technique, ${ }^{6}$ and root section through the middle or posterior cranial fossa is generally recognised to be a formidable procedure for this benign condition. Moreover, chemical neurolysis or surgical root section removes the sensation of touch as well as pain from the treated area, and although many patients with longstanding pain gratefully accept numbness of the face after these procedures, some suffer more serious consequences from corneal anaesthesia.

Controlled thermocoagulation is based on the principle that small nerve fibres are more readily inactivated by heat than larger ones, hence A-delta and C fibres carrying pain sensation are destroyed before the larger fibres carrying light touch. ${ }^{7}$ This technique therefore offers the possibility of selectively abolishing the sensation of pain while leaving that of light touch intact. Moreover, from the physiological response obtained by stimulating the electrode at a very low voltage in a conscious patient, it is possible to map out the target area, and, by adjusting the electrode if necessary, the zone of analgesia produced can be restricted to the affected region. From these theoretical considerations, controlled thermocoagulation with destruction of the Gasserian ganglion and its posterior rootlets is better than other surgical procedures. The technique is simple with minimal morbidity, and its effectiveness has been well confirmed in North America. Recurrence of pain after this mode of treatment in other series is known to be $18-22 \%$; the small number in our series might be due to the short follow-up period. Even with a significant recurrence rate this procedure, which can be repeated without difficulty, is preferable ${ }^{8}$ to other techniques that have a higher morbidity rate.

Trigeminal neuralgia is the symptom of a condition with a largely unknown pathology. This effective and relatively harmless technique of thermocoagulation offering symptomatic relief is a welcome adjunct to neurosurgery.

We are grateful to Mr L P Lassman, and Professor J Hankinson, for their encouragement of this work; Dr J D Whitby, who formulated the anaesthetic regimen; and $\mathrm{Mr} \mathrm{L} \mathrm{Smith,} \mathrm{chief} \mathrm{electronics} \mathrm{technician,}$ for his technical help.

\section{References}

${ }^{1}$ Blom, S, Archives of Neurology, 1963, 9, 285.

2 Sweet, W H, and Wepsic, J G, Fournal of Neurosurgery, 1974, 39, 143.

3 Onofrio, B M, Fournal of Neurosurgery, 1975, 42, 132.

' Jefferson, A, Fournal of Neurology, Neurosurgery and Psychiatry, 1963, 26, 345.

5 Penman, J, Lancet, 1953, 1, 760.

${ }^{6}$ White, J C, and Sweet, W H, Pain and the Neurosurgeon: A forty year experience. Springfield, Illinois, Charles C Thomas, 1969.

${ }^{7}$ Letcher, F S, and Goldring, S, fournal of Neurosurgery, 1968, 29, 42.

${ }^{8}$ Menzel, J, Piotrowski, W, and Penzholz, H, fournal of Neurosurgery, $1975,42,140$.

(Accepted 23 November 1976) 